\title{
High-risk features in radiation-associated breast angiosarcomas
}

\author{
S P D'Angelo*,1,2, C R Antonescu ${ }^{3}, \mathrm{D} \mathrm{Kuk}{ }^{4}, \mathrm{~L} \mathrm{Qin}^{4}, \mathrm{~N} \mathrm{Moraco}{ }^{5}, \mathrm{R}$ C Carvajal ${ }^{1,2}, \mathrm{P} \mathrm{Chi}{ }^{1,2}, \mathrm{M}$ A Dickson ${ }^{1,2}$, \\ M Gounder ${ }^{1,2}$, M L Keohan ${ }^{1,2}$, S Singer ${ }^{5}$, G K Schwartz ${ }^{1,2}$ and W D Tap ${ }^{1,2}$ \\ ${ }^{1}$ Department of Medicine, Memorial Sloan-Kettering Cancer Center, 1275 York Avenue, New York, NY 10065, USA; ${ }^{2}$ Weill Cornell \\ Medical College, 1300 York Avenue, New York, NY 10065, USA; ${ }^{3}$ Department of Pathology, Memorial Sloan-Kettering Cancer \\ Center, 1275 York Avenue, New York, NY 10065, USA; ${ }^{4}$ Department of Epidemiology and Biostatistics, Memorial Sloan-Kettering \\ Cancer Center, 1275 York Avenue, New York, NY 10065, USA and ${ }^{5}$ Department of Surgery, Memorial Sloan-Kettering Cancer \\ Center, 1275 York Avenue, New York, NY 10065, USA
}

Background: Radiation-associated breast angiosarcoma (RT-AS) is an uncommon malignancy with an incidence of less than $1 \%$ of all soft tissue sarcomas. The overall prognosis is quite dismal with high rates of recurrences and poor overall survival. There is an obvious paucity of data regarding clinical outcomes of patients with breast RT-AS.

Methods: We identified all patients with RT-AS treated at the Memorial Sloan-Kettering Cancer Center between 1982-2011 and collected their correlative clinical information.

Results: We identified 79 women with RT-AS with a median age of 68 (range 36-87). The median interval between radiation and development of RT-AS was 7 years (range 3-19). The median time to local and distant recurrence was 1.29 years (95\% $\mathrm{Cl} 0.72-\mathrm{NA})$ and 2.48 years $(95 \% \mathrm{Cl} 1.29-\mathrm{NA})$, respectively. The median disease-specific survival was 2.97 years ( $95 \% \mathrm{Cl} 2.21-\mathrm{NA})$. Independent predictors of worse disease-specific survival included age $\geqslant 68$ years ( $\mathrm{HR} 3.11,95 \% \mathrm{Cl} 1.20-8.08, P=0.020$ ) and deep tumors (HR 3.23, $95 \% \mathrm{Cl} 1.02-10.21, P=0.046$.)

Conclusion: RT-AS has high local/distant recurrence rates, limited duration on standard chemotherapy and poor disease-specific survival.

Angiosarcomas (ASs) are rare, aggressive malignancies of endothelial cell differentiation that constitute 1 to $2 \%$ of all soft tissue sarcomas (Young et al, 2010). The incidence of AS has equal gender distribution but occurs more commonly in older patients (Mark et al, 1996; Fury et al, 2005; Rouhani et al, 2008). Tumors can occur at any soft tissue site or viscera; while cutaneous lesions are frequently found in the areas exposed to radiation or in the head and neck region, typically the scalp (Young et al, 2010). Surgical resections are rarely curative, local recurrence and distant metastases are common. The overall 5-year survival is $35 \%$ (Mark et al, 1996; Fury et al, 2005; Fayette et al, 2007). Typical cytotoxic agents such as anthracyclines and taxanes are reserved for unresectable disease, with response rates of about $15 \%$. Targeting angiogenesis in AS has been evaluated with bevacizumab and sorafenib with response rates of around $14 \%$ (Maki et al, 2009; Agulnik et al, 2013).
Secondary breast AS occurs in older women with a prior history of breast cancer management including axillary dissection and/or radiation therapy (Hobbs et al, 1984). Historically, Stewart Treves syndrome was attributed to the development of AS in the setting of lymphedema (Hobbs et al, 1984). Subsequently, secondary AS occurred more frequently in the irradiated field after breast conserving therapy (Billings et al, 2004). There are criteria used to qualify a malignancy as radiation-induced: (1) prior history of radiation in the tissue where the malignancy arises; (2) long latency period between the radiation and the diagnosis; (3) the new diagnosis is pathologically different from the primary malignancy (Cahan et al, 1948). The first case of radiation-associated angiosarcoma (RT-AS) of the breast was reported in 1981 (Maddox and Evans, 1981). RT-AS is uncommon with an incidence of less than $1 \%$ of all soft tissue sarcomas. In women with a prior history of breast cancer, the adjusted odds ratio for the

*Correspondence: Dr SP D'Angelo; E-mail: dangelos@mskcc.org

Received 19 June 2013; revised 25 August 2013; accepted 4 September 2013; published online 8 October 2013

(c) 2013 Cancer Research UK. All rights reserved 0007-0920/13 
development of breast or chest angiosarcoma was estimated to be 11.6 (95\% CI $=4.3-26.1$ ) (Cozen et al, 1999). Nonetheless, the incidence may be increasing as more patients undergo breastconserving therapy and radiation.

RT-ASs of the breast are typically cutaneous lesions that often appear along the surgical scar as discolored skin changes (Cozen et al, 1999). The clinical presentation can vary, there can be an erythematous plaque, patch or nodule with overlying edema and at times, have an ecchymotic appearance (Lucas, 2009). There can often be diffuse involvement of the breast (Lucas, 2009). It occurs with a median latency of approximately $4-8$ years (Seinen et al, 2012). The overall prognosis is quite dismal with high rates of recurrences approaching $70-73 \%$ and poor median overall survival, ranging from 1.5-3 years with a 5-year OS of $15 \%$ (Strobbe et al, 1998; Marchal et al, 1999; Adhikari et al, 2002; Rao et al, 2003; Monroe et al, 2003; Billings et al, 2004; Hodgson et al, 2007). There is an obvious paucity of data regarding clinical outcomes of patients with breast RT-AS. A recent series by the MD Anderson group included 95 patients, however only 59 of those patients had disease limited to the breast only, while the remaining had chest wall, axillary or arm disease (Torres et al, 2013).

In order to gain a better understanding of the natural history and clinical outcomes of RT-AS, we performed a retrospective analysis of all patients seen at our institution over the last 30 years. We sought to define high risk features in a population of patients with RT-AS. We reviewed the clinical characteristics, prognostic factors and treatment outcomes associated with disease-specific survival, local and distant recurrences and evaluated median treatment time on systemic chemotherapy.

\section{MATERIALS AND METHODS}

Using our institutional sarcoma database and data query system, we identified 79 patients with RT-AS of the breast treated at Memorial Sloan-Kettering Cancer Center between 1982-2011. All patients had received radiation therapy for a prior history of breast cancer. The doses and modality of radiation therapy were not known. The diagnosis of radiation-associated angiosarcoma was defined pathologically by the presence of solid growth with variable angioformative features and overt cytologic atypia.

The following patient characteristics were reviewed: age at the time of diagnosis, presentation status (primary, recurrent-local, recurrent-metastatic), type of initial surgery, primary tumor size, margin status, depth, interval from radiation therapy to presentation of AS and chemotherapy history. The largest dimension of the primary tumor determined pathologically defined the tumor size; it was also stratified as $\leqslant 5,5-10$ or $>10 \mathrm{~cm}$. Margins were characterized as $\mathrm{R} 0=$ negative, $\mathrm{R} 1=$ microscopically positive or $\mathrm{R} 2=$ grossly positive. RT-AS are typically cutaneous superficial tumors.

Anatomic depth was evaluated relative to the investing superficial fascia and deep-seated tumors are defined by the infiltration of fascial place into skeletal muscle.

First-line chemotherapy history was documented as the median treatment time-on-therapy based on the start and end date of each regimen.

Statistical analysis. Patient characteristics are presented by frequencies and percentages for categorical variables, and median and range for continuous variables. The Kaplan-Meier and logrank test were used to calculate survival probabilities and compare survival between groups. The primary endpoint of the analysis was disease-specific survival, calculated as time from surgery to death due to disease or last follow-up. Patients who died of other causes are censored. Local recurrence-free survival was calculated as time from surgery to date of first local recurrence or date of last follow-up for patients that presented with primary disease, underwent surgery and had negative gross margins. Distant recurrence-free survival was calculated as time from surgery to date of first distant recurrence or date of last follow-up for patients that presented with primary disease. Variables significant in the univariate setting were included in a multivariate Cox Proportional Hazards Model. $P$-values $<0.05$ were considered significant. All statistical analysis was done using $\mathrm{R}$ version 3.0.0, including the survival package.

\section{RESULTS}

Patient characteristics. The cohort included 79 women with breast RT-AS with a median age of 68 (range 36-87) at the time of diagnosis (Table 1). The median follow-up amongst those alive at last follow-up was 4.5 years. The median interval between the administration of radiation therapy and development of RT-AS was 7 years (range 3-19.) Doses of radiation therapy were not available. At presentation, the majority of patients, 74 out of 79 (94\%) had primary disease, while 2 out of 79 (3\%) had a local recurrence and 3 out of $79(4 \%)$ had metastatic disease. Most patients, 65 out of $79(82 \%)$, underwent a mastectomy as initial surgery and 13 out of $79(16 \%)$ underwent a wide local excision. Initial surgery was performed at MSKCC on 50 out of 79 (63\%) patients. Tumor size was $\leqslant 5 \mathrm{~cm}$ in 46 out of $79(58 \%)$ patients, $6-10 \mathrm{~cm}$ in 18 out of $79(23 \%)$ patients, $>10 \mathrm{~cm} 12$ out of $79(15 \%)$ patients and unknown in 3 out of 79 (4\%). Microscopic margins were negative in 52 out of 79 patients (ie $66 \%$ of cases). Grade was not evaluated because all radiation-associated angiosarcomas are considered to be of high grade tumors (Espat et al, 2000).

Disease-specific survival. Data analysis was performed on 65 out of 74 patients because 9 patients lacked data in regards to their surgical history or dates of follow-up. The median disease-specific survival (DSS) patients that presented with primary disease was 3 years (95\% CI: 2.21, NA) (Figure 1). The 1-, 2- and 5-year DSS was $84 \%$ (95\% CI $0.74-0.94), 66 \%$ (95\% CI $0.54-0.81)$ and $47 \%$ (95\% CI $0.33-0.65)$ respectively. At a median follow-up of 4.5 years, 28 out of $65(43 \%)$ patients had died of the disease.

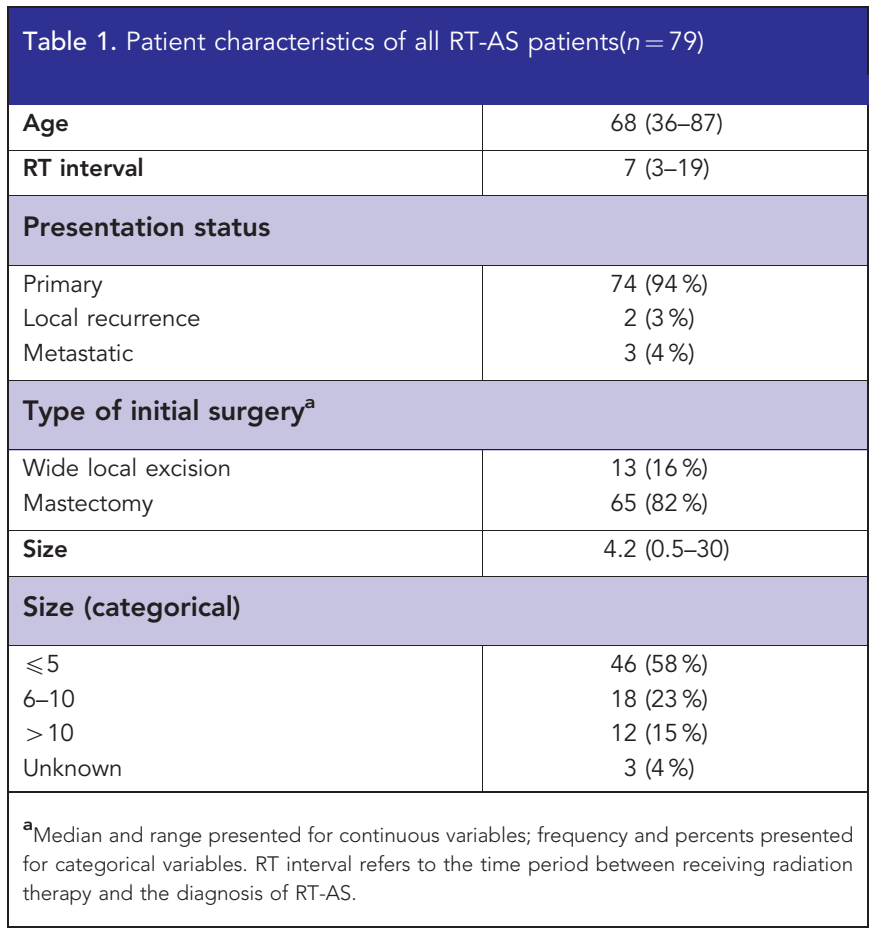




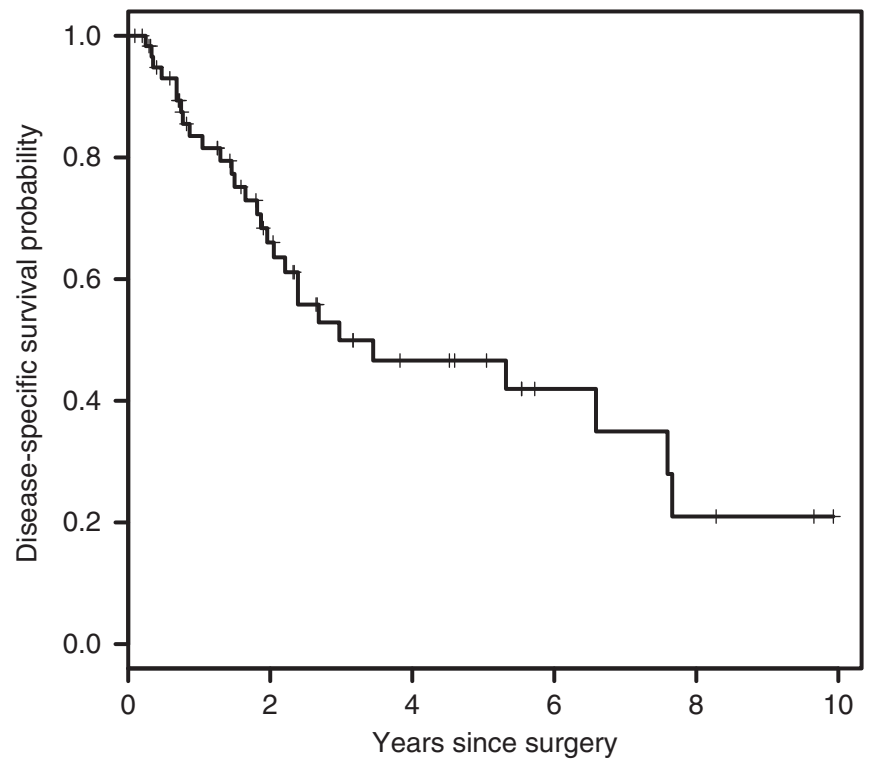

Figure 1. The Kaplan-Meier curve of disease-specific survival for all patients presenting with primary disease ( $n=65$; median 3 years).

Pathological data was unavailable in some patients thereby accounting for the variability in the denominator in each prognostic factor. On univariate analysis, prognostic markers of age, depth and size were significant variables (Table 2a). The median DSS of younger patients ( $<68$ years) was significantly higher compared with older patients (7.66 vs 2.05 years, $P=0.0003)$. Patients with superficial tumors had improved DSS compared with those having deep tumors (5.32 vs 0.77 years, $P=0.0015)$. The median DSS of those with tumors $\leqslant 5 \mathrm{~cm}$ was 6.59 vs 3.45 years, and 1.28 years in those with tumors $5-10$ and $>10 \mathrm{~cm}$, respectively, $P=0.0009$. Age of $\geqslant 68$ years and deep tumors were independently associated with worse DSS with hazard ratios of $3.11(95 \% \mathrm{CI} 1.20-8.08, P=0.02)$ and $3.23(95 \% \mathrm{CI}$ $1.02-10.21, P=0.05)$, respectively (Table $2 b$ ).

Recurrence-free survival. There were 56 out of 74 patients that presented with primary disease, underwent surgery, had negative gross margins and had available data necessary for analysis (Table 3). The 1-, 2-, and 5-year local recurrence-free survival (LRFS) were $55 \%$ (95\% CI $0.42-0.72$ ), $45 \%$ (95\% CI $0.32-0.64$ ) and $41 \%$ (95\% CI $0.27-0.61)$, respectively. There were 25 out of 56 (45\%) patients with a LRFS at a median time of 1.29 years, (95\% CI 0.72-NA) (Figure 2). Second and third local recurrences occurred in 8 out of $25(32 \%)$ and 2 out of $8(25 \%)$ patients with a median interval between recurrences of 1.29 and 0.28 years, respectively (Table 4 ). On univariate analysis, patients with deep tumors had worse LRFS compared with those having superficial tumors (0.52 vs 2.34 years, $P=0.035)$.

There were 70 patients included in the analysis for distant recurrence; four patients were excluded due to missing data (Table 5). The 1-, 2- and 5-year distant recurrence free-survival (DRFS) are $66 \%$ (95\% CI 0.55-0.80), $54 \%$ (95\% CI $0.42-0.69$ ) and $48 \%$ (95\% CI $0.35-0.64)$, respectively. There were 29 out of 70 (41\%) patients who had a distant recurrence, with the median DRFS of 2.48 years (95\% CI 1.29-NA) (Figure 3). Metastatic sites at the time of distant recurrence included: ipsilateral lymph nodes $(n=10)$, contralateral breast/lymph nodes $(n=8)$, lung/pleura/ mediastinum $(n=9)$, bone $(n=5)$, liver $(n=3)$ and other $(n=3)$. On univariate analysis, patients with gross negative margins had improved DRFS compared to those with gross positive margins (2.48 vs 0.49 years, $P=0.0004$ ). Of the 28 patients that died of disease, 12 of these patients had distant recurrences, 9 patients had

\begin{tabular}{|c|c|c|c|c|c|}
\hline Variable & $\mathbf{N}$ & Died, $\mathbf{N}$ & $\begin{array}{l}\text { Median } \\
\text { DSS, yr }\end{array}$ & $95 \% \mathrm{Cl}$ & $\begin{array}{l}\text { Log-rank } \\
P \text {-value }\end{array}$ \\
\hline All pts & 65 & 28 & 2.97 & $(2.21, \mathrm{NA})$ & \\
\hline Age (continuous) & 65 & 28 & & & 0.0011 \\
\hline \multicolumn{6}{|l|}{ Age } \\
\hline$\leqslant 68$ & 34 & 10 & 7.66 & $(5.32, N A)$ & \multirow[t]{2}{*}{0.0003} \\
\hline$>68$ & 31 & 18 & 2.05 & $(1.46, N A)$ & \\
\hline \multicolumn{6}{|l|}{ Depth } \\
\hline Superficial & 46 & 15 & 5.32 & $(2.39, \mathrm{NA})$ & \multirow[t]{2}{*}{0.0015} \\
\hline Deep & 12 & 9 & 0.77 & $(0.68, N A)$ & \\
\hline \multicolumn{6}{|l|}{ Size } \\
\hline$\leqslant 5 \mathrm{~cm}$ & 37 & 13 & 6.59 & $(2.39, N A)$ & \multirow[t]{3}{*}{0.0009} \\
\hline$>5 \mathrm{~cm}, \leqslant 10 \mathrm{~cm}$ & 16 & 7 & 3.45 & $(1.96, N A)$ & \\
\hline$>10 \mathrm{~cm}$ & 10 & 6 & 1.28 & $(0.68, N A)$ & \\
\hline \multicolumn{6}{|c|}{ Micro Margin (R0) } \\
\hline Yes & 19 & 10 & 3.45 & $(1.96, \mathrm{NA})$ & \multirow[t]{2}{*}{0.64} \\
\hline No & 44 & 16 & 6.59 & $(2.21, N A)$ & \\
\hline \multicolumn{6}{|c|}{ Gross Margin (R1) } \\
\hline Yes & 9 & 4 & 2.39 & $(1.05, \mathrm{NA})$ & \multirow[t]{2}{*}{0.387} \\
\hline No & 54 & 22 & 5.32 & $(2.39, N A)$ & \\
\hline \multicolumn{6}{|l|}{ Adjuvant Chemo } \\
\hline No & 56 & 23 & 3.45 & $(2.39, \mathrm{NA})$ & \multirow[t]{2}{*}{0.583} \\
\hline Yes & 9 & 5 & 1.87 & $(1.05, \mathrm{NA})$ & \\
\hline
\end{tabular}

Table 2b. Multivariate analysis of disease-specific survival in patients presenting with primary disease

\begin{tabular}{|l|c|c|c|c|c|}
\hline Variable & $\begin{array}{c}\text { N } \\
\text { used }\end{array}$ & $\begin{array}{c}\text { N } \\
\text { event }\end{array}$ & HR & $95 \%$ Cl & P-value \\
\hline Age (>68 vs $\leqslant 68)$ & 58 & 24 & 3.11 & $(1.20,8.08)$ & 0.020 \\
\hline Depth (Deep vs Superficial) & 58 & 24 & 3.23 & $(1.02,10.21)$ & 0.046 \\
\hline Size & 58 & 24 & & & \\
\hline$>5 \mathrm{~cm}, \leqslant 10 \mathrm{~cm}$ vs $\leqslant 5 \mathrm{~cm}$ & & & 1.26 & $(0.48,3.31)$ & 0.635 \\
\hline$>10 \mathrm{~cm}$ vs $\leqslant 5 \mathrm{~cm}$ & & & 1.98 & $(0.51,7.75)$ & 0.327 \\
\hline
\end{tabular}

both distant and local recurrences, and seven patients had local recurrences (Figure 4).

Treatment outcomes. There were 23 out of 79 patients that received chemotherapy for unresectable or metastatic disease. Patients often received several lines of therapy. Median treatment time (MTT) was defined as the total duration on first-line chemotherapy, determined by the start and end date of each regimen. For all patients, it ranged from 1.32 months to 25 months. Chemotherapy regimens for all RT-AS patients are summarized (Table 6). Liposomal doxorubicin was the most commonly administered regimen and had a MTT of 4.67 months. MTT was noted to be of 25.1 months, 3.45 months and 3.34 months for sorafenib $(n=3)$, paclitaxel $(n=3)$ and brivanib $(n=2)$, respectively. There was also one patient that received sirolimus for 15 months. A Kruskal-Wallis test was performed that compared 
Table 3. Univariate analysis of local recurrence-free survival in patients who presented with primary disease, underwent surgery and had negative gross margins

\begin{tabular}{|c|c|c|c|c|c|}
\hline Variable & $\mathbf{N}$ & $\begin{array}{c}\text { Local } \\
\text { recurrence, } \\
\mathbf{N}\end{array}$ & $\begin{array}{c}\text { Median } \\
\text { local } \\
\text { RFS, yr }\end{array}$ & $95 \% \mathrm{Cl}$ & $\begin{array}{c}\text { Log-rank } \\
P \text {-value }\end{array}$ \\
\hline All pts & 56 & 25 & 1.29 & $(0.72, N A)$ & \\
\hline \multicolumn{6}{|l|}{ Depth } \\
\hline $\begin{array}{l}\text { Superficial } \\
\text { Deep }\end{array}$ & $\begin{array}{l}40 \\
11\end{array}$ & $\begin{array}{r}16 \\
8\end{array}$ & $\begin{array}{l}2.34 \\
0.52\end{array}$ & $\begin{array}{l}(0.75, \mathrm{NA}) \\
(0.14, \mathrm{NA})\end{array}$ & 0.035 \\
\hline \multicolumn{6}{|l|}{ Size } \\
\hline $\begin{array}{l}\leqslant 5 \mathrm{~cm} \\
>5 \mathrm{~cm}, \leqslant 10 \mathrm{~cm} \\
>10 \mathrm{~cm}\end{array}$ & $\begin{array}{r}34 \\
13 \\
8\end{array}$ & $\begin{array}{r}14 \\
5 \\
5\end{array}$ & $\begin{array}{l}2.34 \\
\text { NA } \\
0.52\end{array}$ & $\begin{array}{l}(0.74, N A) \\
(0.59, N A) \\
(0.40, N A)\end{array}$ & 0.077 \\
\hline \multicolumn{6}{|l|}{ Margin status } \\
\hline $\begin{array}{l}\text { R0 } \\
\text { R1 }\end{array}$ & $\begin{array}{l}44 \\
12\end{array}$ & $\begin{array}{r}17 \\
8\end{array}$ & $\begin{array}{l}2.34 \\
0.59\end{array}$ & $\begin{array}{l}(0.75, N A) \\
(0.48, N A)\end{array}$ & 0.322 \\
\hline \multicolumn{6}{|c|}{ Adjuvant Chemo } \\
\hline $\begin{array}{l}\text { No } \\
\text { Yes }\end{array}$ & $\begin{array}{r}51 \\
4 \\
\end{array}$ & $\begin{array}{r}22 \\
2\end{array}$ & $\begin{array}{l}1.94 \\
0.74\end{array}$ & $\begin{array}{l}(0.72, \mathrm{NA}) \\
(0.48, \mathrm{NA})\end{array}$ & 0.706 \\
\hline
\end{tabular}

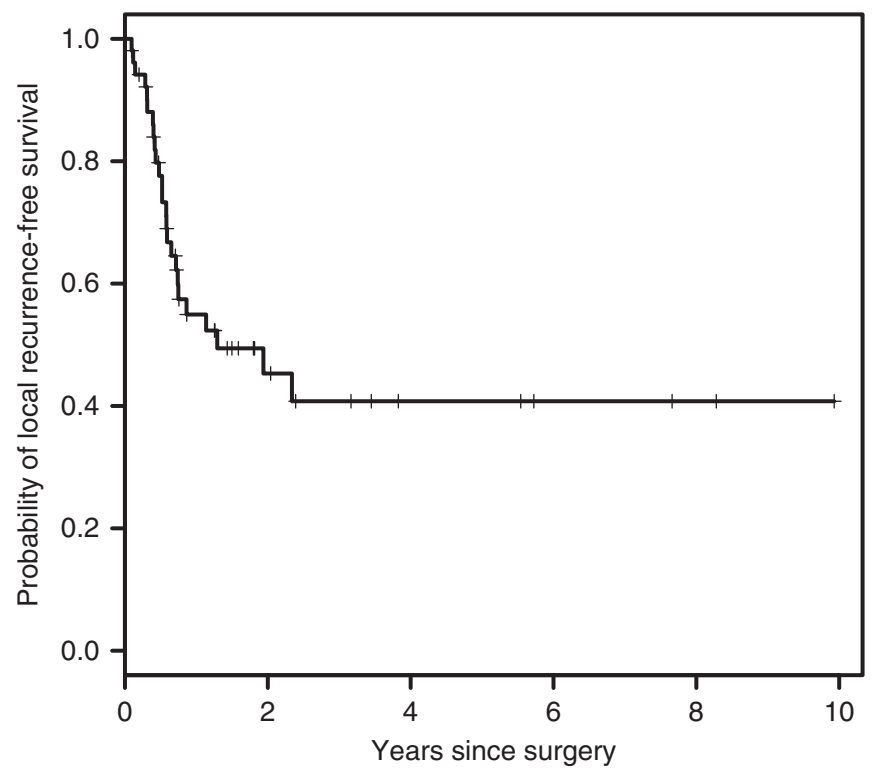

Figure 2. The Kaplan-Meier curve of the probability of local recurrence for all patients presenting with primary disease, underwent surgery and had negative gross margins ( $n=56$; median 1.29 years).

Table 4. RT-AS patients, recurrence patterns in patients presenting with primary disease

\begin{tabular}{|l|c|c|}
\hline Recurrence & & Median RFS, years \\
\hline Local & $25 / 56(45 \%)$ & 1.29 \\
\hline Metastatic & $29 / 70(41 \%)$ & 2.48 \\
\hline No of local recurrences & & $\begin{array}{c}\text { Median interval between } \\
\text { LR, years }\end{array}$ \\
\hline 1 & $25 / 56(45 \%)$ & 1.29 \\
\hline 2 & $8 / 56(14 \%)$ & 1.29 \\
\hline 3 & $2 / 56(4 \%)$ & 0.28 \\
\hline
\end{tabular}

Table 5. Univariate analysis of distant recurrence-free survival in patients presenting with primary disease

\begin{tabular}{|c|c|c|c|c|c|}
\hline Variable & $\mathbf{N}$ & $\begin{array}{c}\text { Distant } \\
\text { recurrence, } \\
\mathbf{N}\end{array}$ & $\begin{array}{c}\text { Median } \\
\text { distant } \\
\text { RFS, yr }\end{array}$ & $95 \% \mathrm{Cl}$ & $\begin{array}{c}\text { Log-rank } \\
P \text {-value }\end{array}$ \\
\hline All pts & 70 & 29 & 2.48 & $(1.29, \mathrm{NA})$ & \\
\hline \multicolumn{6}{|l|}{ Depth } \\
\hline Superficial & 47 & 18 & 2.34 & $(1.29, \mathrm{NA})$ & \multirow{2}{*}{0.834} \\
\hline Deep & 14 & 5 & NA & $(0.40, N A)$ & \\
\hline \multicolumn{6}{|l|}{ Size } \\
\hline$\leqslant 5 \mathrm{~cm}$ & 40 & 17 & 2.34 & $(0.99, N A)$ & \multirow[t]{3}{*}{0.936} \\
\hline$>5 \mathrm{~cm}, \leqslant 10 \mathrm{~cm}$ & 16 & 6 & NA & $(1.31, N A)$ & \\
\hline$>10 \mathrm{~cm}$ & 11 & 3 & NA & $(1.05, \mathrm{NA})$ & \\
\hline \multicolumn{6}{|c|}{ Margin status } \\
\hline RO & 45 & 17 & 2.48 & $(1.21, N A)$ & \multirow[t]{3}{*}{0.0004} \\
\hline R1 & 12 & 2 & NA & NA & \\
\hline R2 & 8 & 6 & 0.49 & $(0.32, N A)$ & \\
\hline \multicolumn{6}{|c|}{ Adjuvant Chemo } \\
\hline No & 61 & 23 & 5.71 & $(1.54, N A)$ & \multirow[t]{2}{*}{0.291} \\
\hline Yes & 9 & 6 & 1.05 & $(0.65, \mathrm{NA})$ & \\
\hline
\end{tabular}

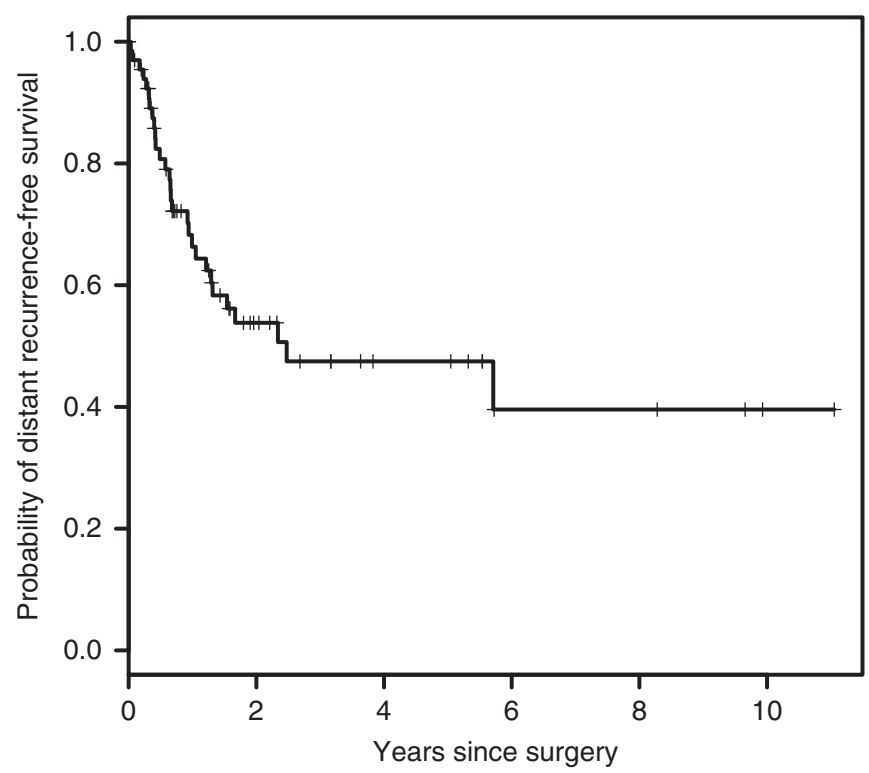

Figure 3. The Kaplan-Meier curve of the probability of distant recurrence for all patients presenting with primary disease $(n=70$; median 2.48 years).

the MTT of anthracyclines (2.96 months) vs taxanes (3.01 months), $P=0.446$. There was no statistically signficant difference in the MTT amongst first-line anthracyclines and taxanes.

\section{DISCUSSION}

To our knowledge, this is the largest retrospective series evaluating clinical characteristics, prognostic factors and treatment outcomes with surgery and chemotherapy in patients with RT-AS of the breast. We have identified 79 patients treated at a single institution over a 30-year period. A recent series by MD Anderson included 
Distant recurrences Local recurrences Both

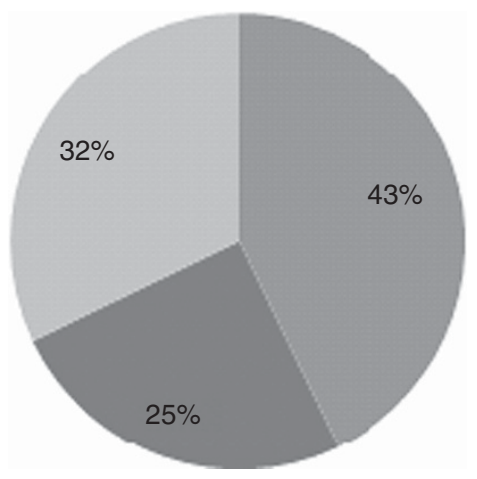

Figure 4. Type of recurrences among patients presenting with primary disease and died from the disease (total deaths $n=28$ ).

\begin{tabular}{|c|c|c|}
\hline $\begin{array}{l}\text { Chemotherapy } \\
\text { regimen }\end{array}$ & $\begin{array}{c}\text { Administrations, } \\
\mathbf{N}\end{array}$ & $\begin{array}{l}\text { Median treatment } \\
\text { time, months }\end{array}$ \\
\hline Brivanib & 2 & 3.34 \\
\hline Doxorubicin & 2 & 2.07 \\
\hline Doxorubicin/Paclitaxel & 1 & 5.16 \\
\hline Gemcitabine & 0 & - \\
\hline Gemcitabine/Docetaxel & 1 & 2.57 \\
\hline Ifosfamide & 1 & 1.32 \\
\hline Liposomal Doxorubicin & 7 & 4.67 \\
\hline Paclitaxel & 3 & 3.45 \\
\hline Sirolimus & 1 & 14.93 \\
\hline Sorafenib & 3 & 25.1 \\
\hline
\end{tabular}

95 patients with RT-AS; 59 patients had disease localized to the breast only, while 36 patients had disease of the chest wall, arm and axilla (Torres et al, 2013). The one-and five-year DSS rates in that study were $93.5 \%$ and $62.6 \%$, respectively. Interestingly, more than $50 \%$ of their patients received neoadjuvant or adjuvant chemotherapy and they demonstrated a decreased risk of local recurrence with chemotherapy. Larger size was identified as an independent predictor of worse DSS (Torres et al, 2013). Outcome of chemotherapy in the metastatic setting was not evaluated.

We have demonstrated a median disease-specific survival of 2.97 years. This is relatively consistent with previously published reports which describe a median survival ranging from $1-3$ years (Monroe et al, 2003). Our 1-, 2- and 5-year DSS was $84 \%, 66 \%$ and $47 \%$, repectively; this is worse compared with other published series (Monroe et al, 2003; Billings et al, 2004; Abraham et al, 2007; Torres et al, 2013). Although not previously demonstrated in this disease, we've shown that age and depth are independent predictors of DSS. Generally, RT-AS is thought of as a cutaneous disease. Pathologic analysis did reveal that some tumors can invade muscularis layers, these were characterized as deep tumors and they appeared to behave more aggressively.

Recurrence patterns were notable for development of first local recurrence in 25 out of 56 (45\%) of patients, with a median local RFS of 1.29 years and one-year local RFS rate of $55 \%$. There was a smaller published series which demonstrated a one-year local recurrence rate of $84 \%$, however, the majority of their patients did not undergo a mastectomy (Monroe et al, 2003). In the MD Anderson series, the local recurrence rate was noted to be $48 \%$ with a median of 1.8 years which appears more similar to our findings. Interestingly, that series did include patients with both R0 and $\mathrm{R} 1$ resections (Torres et al, 2013). We did not identify margin status as a predictor of local recurrence; and instead only depth was noted to be significant on univariate analysis. Regardless of the type of resection, there remains a high rate of local recurrence. This points to the multifocal, infiltrative nature of this disease and may suggest that surgery alone may not be curative. Further, we did identify that $25 \%$ of patients with local recurrences ultimately die of their disease. Therefore, aggressive management of a local recurrence is necessary. Consideration of systemic chemotherapy prior to further surgical resection may be warranted.

Distant recurrences occurred as well. The median distant RFS was 2.48 years and 29 out of 70 (40\%) patients developed distant recurrences. Patients with an R2 resection did have worse DRFS as compared with those having a R0 resection (0.49 vs 2.48 years, $P=0.0004)$. Perhaps patients with R2 margins had larger, more infiltrative tumors that were more aggressive or a higher likelihood of micro-metastases which led to distant recurrences. There was a subset of patients that developed late distant recurrences more than 5 years after diagnosis. Therefore, patients do require long-term follow-up beyond 5 years. This poses some challenges in regards to the appropriate interval of imaging studies and necessitates a thorough discussion of the risks and benefits of these studies.

In our series, there were few patients that received neoadjuvant/ adjuvant chemotherapy. Those who did receive chemotherapy appeared to have worse local and distant recurrence rates, although not statistically significant. Perhaps those that received chemotherapy had more aggressive tumors which impacted on the poorer outcomes observed. The rationale of selection of these particular patients for adjuvant therapies is not clear. Therefore, the potential impact of adjuvant chemotherapy is not possible to interpret, given the small numbers. The MD Anderson series noted a decrease in local recurrence in patients that received adjuvant chemotherapy and surgery, hazard ratio 0.35 ; (95\% CI $0.15-0.8, P=0.012$ ). (Torres et al, 2013). They reported on 31 patients that received chemotherapy. All had large and/or high grade lesions, or margins $<1 \mathrm{~cm}$. Adjuvant chemotherapy did not impact DSS. Ultimately, prospective data would be necessary to truly evaluate this important question. Further, there remains the need for more effective systemic therapies.

Our series is the first analysis to evaluate chemotherapy outcomes specifically in breast RT-AS patients. Compared with all AS patients, the MTT seems to be slightly worse with standard cytotoxic chemotherapy agents. This is consistent with the generally worse outcome that these patients have. In this series, the MTT ranged from 1.32 to 25.1 months. Sorafenib had the longest MTT of 25.1 months. The most commonly used chemotherapy regimen was liposomal doxorubicin which had a MTT of 4.67 months. Monotherapy with doxorubicin had a MTT of 2.07 months. In all types of AS, anthracycline based regimens had slightly improved outcomes, with MTT ranging from 3.7 to 5.4 months (Fury et al, 2005). Paclitaxel had a mean MTT of 3.45 months which is slightly lower than the 4 months median time to progression for all AS patients as demonstrated in the ANGIOTAX study (Penel et al, 2008). The lack of prospective data in this disease precludes determination of the most effective standard chemotherapeutic agents. In the era of oral tyrosine kinase inhibitors, evaluation of these agents is warranted as well; as we noted some interesting observations with agents such as sorafenib, brivanib and sirolimus.

Sorafenib demonstrated the longest MTT of 25.1 months. There were three patients that received sorafenib, remaining on drug for $46.9,25.1$ and 4.38 months. In a phase II study of sorafenib in 
patients with soft tissue sarcoma, patients with angiosarcoma had a progression-free survival of 3.8 months (Maki et al, 2009). Sorafenib inhibits RAF, VEGF 1-3, PDGFR $\beta$, FLT-3, c-KIT and RET (Wilhelm et al, 2004; Carlomagno et al, 2006). Further, pre-clinical data has demonstrated that sorafenib also targets cyclin D1, MYC and BCL-2 (Delgado et al, 2008). In a small series of RT-AS breast patients, we have demonstrated that sorafenib may have improved responses and longer duration times in patients that harbor MYC and FLT4 co-amplifications (D'Angelo et al, 2012).

Two patients received brivanib on a clinical trial; the MTT was 3.34 months. Brivanib is an oral dual inhibitor of VEGF and fibroblast growth factor (FGF) that was evaluated in a phase II-randomized discontinuation trial in advanced soft tissue sarcomas (Schwartz et al, 2011). In that study, patients that had FGF2 expression by immunohistochemistry appeared to potentially benefit; there was also a suggestion of increased activity in angiosarcoma. A recent phase II trial of bevacizumab, a VEGF inhibitor in angiosarcomas has demonstrated a median time to progression of 14 weeks (Agulnik et al, 2013). Perhaps the disease stability rates with angiogenic inhibitors may reflect the commonality in the mechanisms of these agents and its impact on the pathophysiology of angiosarcoma.

Single agent sirolimus was found to have MTT 14.93 months in one patient. Sirolimus inhibits the mammalian target of rapamycin (mTOR) pathway by directly binding the mTOR complex 1 . The overexpression of phosphorylated ribosomal protein S6 kinase and phosphorylated eukaryotic translation initiation factor $4 \mathrm{E}$ binding protein 1 ( $\mathrm{p}-4 \mathrm{eBP} 1$ ) in has been described in $42 \%$ of AS patients, suggesting the activation of $\mathrm{PIK} 3 \mathrm{CA} / \mathrm{AKT} / \mathrm{mTOR}$ pathway (Italiano et al, 2012). The slightly improved outcomes with biological agents such as brivanib, sorafenib and temsirolimus in RT-AS may be suggestive of the underlying molecular biology of this disease, and application of these inhibitors warrants further exploration.

This is a small, single institution retrospective series with several limitations. Given the rarity of this disease, the study is primarily descriptive. We did not have the dose or modalities of radiation available, as it was most commonly received at an outside institution. Therefore, we were unable to correlate radiation to clinical characteristics and treatment outcomes. In addition, there have been many changes with radiation technology and evaluating the date of radiation treatment with an outcome may impact results as well. Further, the presence/absence of lymphedema was not well-documented. The efficacy of first-line chemotherapy must also be interpreted with caution. Although best efforts were made to calculate the MTT accurately, the timing of when imaging studies were performed can certainly have an impact on these data. Further, if someone discontinued chemotherapy due to increased toxicity and not disease progression, that too can impact interpretation of results. The role of adjuvant chemotherapy is not interpretable and its potential impact on these results is unclear. The selection of patients for adjuvant chemotherapy was not clearly defined. The efficacy of targeted molecules in this subset of AS was noted to be encouraging and may point to the underlying molecular pathophysiology. Conducting molecular analysis and evaluating their clinical outcomes on all RT-AS patients may lead to interesting observations. This information is helpful in guiding the treatment of our patients. These data should also encourage increased participation in clinical trials given the minimal efficacy of standard agents in RT-AS as well as an essentially undefined therapeutic strategy. These findings can only lay the foundation for more comprehensive and perhaps, prospective analyses in the future.

Moving forward, we are actively testing all of our RT-AS patients for the presence of these molecular changes. We seek to further define the prognostic and predictive nature of these alterations. Performing molecular studies on all AS patients will allow us to define the pathophysiology of this disease and guide rational clinical trials. Although the paradigm of drug development often initiates in the laboratory and moves forward, these observations suggest the significance of bi-directional flow of information to ultimately improve patient outcome.

\section{CONCLUSION}

RT-AS is a rare, but aggressive disease with a dismal prognosis. There is a concern that the incidence may rise if there is an increase in breast-conserving therapies followed by radiation therapy. Currently, there are no data to support this claim. Our data suggest that this is a disease with high local/distant recurrence rates, late recurrences, undefined benefit with chemotherapy and poor survival. Further, patients with local recurrences do die of their disease. This poses some interesting challenges. We noted interesting observations with targeted agents such as sorafenib, brivanib and sirolimus. Further exploration of the molecular pathophysiology to design rationale clinical trials is essential. Ultimately, it is necessary to collaborate to conduct multi-center prospective clinical trials to allow the field to move forward.

\section{CONFLICT OF INTEREST}

The authors declare no conflict of interest.

\section{REFERENCES}

Abraham JA, Hornicek FJ, Kaufman AM, Harmon DC, Springfield DS, Raskin KA, Mankin HJ, Kirsch DG, Rosenberg AE, Nielsen GP, Desphpande V, Suit HD, DeLaney TF, Yoon SS (2007) Treatment and outcome of 82 patients with angiosarcoma. Ann Surg Oncol 14(6): 1953-1967.

Adhikari D, Hajdu SI, Levine D (2002) Post-radiation angiosarcoma and bilateral mastectomy. Ann Clin Lab Sci 32(4): 428-433.

Agulnik M, Von Mehren M, Jovanovic B, Brockstein B, Benjamin RS, Evens AM (2013) An open-label multicenter phase II study of bevacizumab for the treatment of angiosarcoma. Ann Oncol 24: 257-263.

Billings SD, McKenney JK, Folpe AL, Hardacre MC, Weiss SW (2004) Cutaneous angiosarcoma following breast-conserving surgery and radiation: an analysis of 27 cases. Am J Surg Pathol 28(6): 781-788.

Cahan WG, Woodard HQ et al (1948) Sarcoma arising in irradiated bone; report of 11 cases. Cancer 1(1): 3-29.

Carlomagno F, Anaganti S, Guida T, Salvatore G, Troncone G, Wilhelm SM, Santoro M (2006) BAY 43-9006 inhibition of oncogenic RET mutants. J Natl Cancer Inst 98(5): 326-334.

Cozen W, Bernstein L, Wang F, Press MF, Mack TM (1999) The risk of angiosarcoma following primary breast cancer. $\mathrm{Br}$ J Cancer 81(3): 532-536.

D’Angelo SP, Antonescu CR, Keohan ML, Carvajal RD, Dickson MA, Gounder M, Moraco N, Singer S, Schwartz G, Tap WD (2012) Activity of sorafenib in radiation-associated breast angiosarcomas harboring MYC and FLT4 amplifications. J Clin Oncol 30(Suppl): abstract 10019.

Delgado JS, Mustafi R, Yee J, Cerda S, Chumsangsri A, Dougherty U, Lichtenstein L, Fichera A, Bissonnette M (2008) Sorafenib triggers antiproliferative and pro-apoptotic signals in human esophageal adenocarcinoma cells. Digestive Dis Sci 53(12): 3055-3064.

Espat NJ, Lewis JJ, Woodruff JM, Antonescu C, Xia J, Leung D, Brennan MF (2000) Confirmed angiosarcoma: prognostic factors and outcome in 50 prospectively followed patients. Sarcoma 4(4): 173-177.

Fayette J, Martin E, Piperno-Neumann S, Le Cesne A, Robert C, Bonvalot S, Ranchere D, Pouillart P, Coindre JM, Blay JY (2007) Angiosarcomas, a heterogeneous group of sarcomas with specific behavior depending on primary site: a retrospective study of 161 cases. Ann Oncol 18(12): 2030-2036.

Fury MG, Antonescu CR, Van Zee KJ, Brennan MF, Maki RG (2005) A 14-year retrospective review of angiosarcoma: clinical characteristics, 
prognostic factors, and treatment outcomes with surgery and chemotherapy. Cancer J 11(3): 241-247.

Schwartz GK, Maki RG, Ratain MJ, Undevia SD, Jones RL, Rudin CM, Siu LL, Brockstein B, Khayat D, Gil T, De Jonge MJ, Sawyer MB, Evans TRJ, Medioni J, O’Dwyer PJ, Hartman C, Poulart V, Walters IB (2011) Brivanib (BMS-582664) in advanced soft-tissue sarcoma (STS): biomarker and subset results of a phase II randomized discontinuation trial. J Clin Oncol 29(Suppl): abstract 10000.

Hobbs RD, Stewart AF, Ravin ND, Carter D (1984) Hypercalcemia in small cell carcinoma of the pancreas. Cancer 53(7): 1552-1554.

Hodgson NC, Bowen-Wells C, Moffat F, Franceschi D, Avisar E (2007) Angiosarcomas of the breast: a review of 70 cases. Am J Clin Oncol 30(6): 570-573.

Italiano A, Chen CL, Thomas R, Breen M, Bonnet F, Sevenet N, Longy M, Maki RG, Coindre JM, Antonescu CR (2012) Alterations of the p53 and PIK3CA/AKT/mTOR pathways in angiosarcomas: a pattern distinct from other sarcomas with complex genomics. Cancer 118(23): 5878-5887.

Lucas DR (2009) Angiosarcoma, radiation-associated angiosarcoma, and atypical vascular lesion. Arch Pathol Lab Med 133(11): 1804-1809.

Maddox JC, Evans HL (1981) Angiosarcoma of skin and soft tissue: a study of forty-four cases. Cancer 48(8): 1907-1921.

Maki RG, D’Adamo DR, Keohan ML, Saulle M, Schuetze SM, Undevia SD, Livingston MB, Cooney MM, Hensley ML, Mita MM, Takimoto CH, Kraft AS, Elias AD, Brockstein B, Blachere NE, Edgar MA, Schwartz LH, Qin LX, Antonescu CR, Schwartz GK (2009) Phase II study of sorafenib in patients with metastatic or recurrent sarcomas. J Clin Oncol 27(19): 3133-3140.

Marchal C, Weber B, de Lafontan B, Resbeut M, Mignotte H, du Chatelard PP, Cutuli B, Reme-Saumon M, Broussier-Leroux A, Chaplain G, Lesaunier F, Dilhuydy JM, Lagrange JL (1999) Nine breast angiosarcomas after conservative treatment for breast carcinoma: a survey from French Comprehensive Cancer Centers. Int J Radiat Oncol Biol Phy 44(1): 113-119.

Mark RJ, Poen JC, Tran LM, Fu YS, Juillard GF (1996) Angiosarcoma: a report of 67 patients and a review of the literature. Cancer 77(11): 2400-2406.

Monroe AT, Feigenberg SJ, Mendenhall NP (2003) Angiosarcoma after breast-conserving therapy. Cancer 97(8): 1832-1840.

Penel N, Bui BN, Bay JO, Cupissol D, Ray-Coquard I, Piperno-Neumann S, Kerbrat P, Fournier C, Taieb S, Jimenez M, Isambert N, Peyrade F, Chevreau C, Bompas E, Brain EG, Blay JY (2008) Phase II trial of weekly paclitaxel for unresectable angiosarcoma: the ANGIOTAX Study. J Clin Oncol 26(32): 5269-5274.

Rao J, Dekoven JG, Beatty JD, Jones G (2003) Cutaneous angiosarcoma as a delayed complication of radiation therapy for carcinoma of the breast. J Am Acad Dermatol 49(3): 532-538.

Rouhani P, Fletcher CD, Devesa SS, Toro JR (2008) Cutaneous soft tissue sarcoma incidence patterns in the U.S.: an analysis of 12,114 cases. Cancer 113(3): 616-627.

Seinen JM, Styring E, Verstappen V, Vult von Steyern F, Rydholm A, Suurmeijer AJ, Hoekstra HJ (2012) Radiation-associated angiosarcoma after breast cancer: high recurrence rate and poor survival despite surgical treatment with r0 resection. Ann Surg Oncol 19(8): 2700-2706.

Sher T, Hennessy BT, Valero V, Broglio K, Woodward WA, Trent J, Hunt KK, Hortobagyi GN, Gonzalez-Angulo AM (2007) Primary angiosarcomas of the breast. Cancer 110(1): 173-178.

Strobbe LJ, Peterse HL, van Tinteren H, Wijnmaalen A, Rutgers EJ (1998) Angiosarcoma of the breast after conservation therapy for invasive cancer, the incidence and outcome. an unforseen sequela. Breast Cancer Res Tr 47(2): 101-109.

Torres KE, Ravi V, Kin K, Yi M, Guadagnolo BA, May CD, Arun BK, Hunt KK, Lam R, Lahat G, Hoffman A, Cormier JN, Feig BW, Lazar AJ, Lev D, Pollock RE (2013) Long-term outcomes in patients with radiationassociated angiosarcomas of the breast following surgery and radiotherapy for breast cancer. Ann Surg Oncol 20(4): 1267-1274.

Wilhelm SM, Carter C, Tang L, Wilkie D, McNabola A, Rong H, Chen C, Zhang X, Vincent P, McHugh M, Cao Y, Shujath J, Gawlak S, Eveleigh D, Rowley B, Liu L, Adnane L, Lynch M, Auclair D, Taylor I, Gedrich R, Voznesensky A, Riedl B, Post LE, Bollag G, Trail PA (2004) BAY 43-9006 exhibits broad spectrum oral antitumor activity and targets the RAF/ MEK/ERK pathway and receptor tyrosine kinases involved in tumor progression and angiogenesis. Cancer Res 64(19): 7099-7109.

Young RJ, Brown NJ, Reed MW, Hughes D, Woll PJ (2010) Angiosarcoma. Lancet Oncol 11(10): 983-991.

This work is published under the standard license to publish agreement. After 12 months the work will become freely available and the license terms will switch to a Creative Commons AttributionNonCommercial-Share Alike 3.0 Unported License. 